\title{
Consumer buying behaviour: the roles of price, motivation, perceived culture importance, and religious orientation
}

\author{
Mohamed Abdellatif Abu Auf \\ Houcine Meddour \\ Oussama Saoula \\ Abdul Halim Abdul Majid \\ School of Business Management, College of Business \\ Universiti Utara Malaysia, Kedah, Malaysia
}

Key words

Consumer buying Behaviour, price, motivation, perceived culture importance, religious orientation.

\begin{abstract}
Consumer Behaviour issues have become more heterogeneous because of cultural differences. This phenomenon makes it progressively important to understand factors impacting it. As such, this study examined the determinants of consumer buying Behaviour among Saudis and expatriates living in Riyadh; this study discovered the role of price, motivation, perceived culture importance and religious orientation toward consumer buying Behaviour. The study utilises survey questionnaire for data collection from car agencies in Saudi Arabia. The data is analysed using Partial Least Squares (PLS-SEM) technique to test the hypotheses of the study. The empirical findings confirmed the direct relationship between price, motivation, perceived culture importance and consumer buying Behaviour. Besides, price and perceived culture importance were found significantly related to religious orientation. However, contrary to the hypotheses, it is found that the mediating role of religious orientation in the relationship between price, motivation, perceived culture importance and consumer buying Behaviour is not supported. The result is discussed in the context of addressing consumer buying Behaviour in Saudi Arabia.
\end{abstract}

Corresponding author: Abdul Halim Abdul Majid

Email addresses for corresponding author: editor@aessweb.com

First submission received: $7^{\text {th }}$ November 2017

Revised submission received: $4^{\text {th }}$ February 2018

Accepted: $3^{\text {rd }}$ May 2018

\section{Introduction}

Nowadays there is a growing interest in the importance of consumer behaviour in the field of marketing. In today's era of the ever-changing business environment, marketing becomes an important part of any organisation or business (Kaplan \& Haenlein, 2009, Sangroya \& Nayak, 2017, Singh \& Islam, 2017). It contributes greatly to the success of an organisation, enable the creation of business awareness and enhances the level of customer relationship (Verhoef, 2003). Therefore, organisations cannot accomplish their objectives if they have scrawny marketing strategies. And when it comes to marketing strategies, the customer is always bound to be the core. From this, customers have a very crucial role in the success of any organisation since they are the people who generate revenue for the organisation by buying, using and influencing others to buy their products and services (Khaniwale, 2015). Hence, the aim of understanding consumer buying Behaviour is to know the buying decisions of consumers as well as to understand the steps involved in such decisions. Consumer Behaviour is more than just the physical purchase of products but rather covers a wide range of activities from the problem awareness stage through post-purchase Behaviour, ideas formulation, or experiences to satisfy their needs and desires (Orji, Sabo, Abubakar, \& Usman, 2017). As the starting point of marketing strategy, any purchasing decision starts from the opportunity available for any products or services in the market aims to study the market and the customer as well (Kotler, 2010). To do so, many scholars were searching consumer buying Behaviour, as it is needed to be covered and investigated, especially in the third world countries rather than developing countries context (Echtner \& Prasad, 2003, Lai, 2016, Sangroya \& Nayak, 2017, Chowdhury \& Shil, 2017, Khanfir, 2017). The theoretical framework of the current study is grounded on 
the theory of reasoned action (TRA) which was established by (Fishbein \& Ajzen, 1975), which is extended afterwards by Ajzen (1988) to the theory of planned Behaviour (TPB), however, this research applies TPB for the foundation. Preceding studies concentrated on the key constructs of the theory such as attitudes, subjective norms and intentions without adding external variables (Warburton \& Terry, 2000).

\section{Consumer Buying Behaviour}

In the marketing context, it is quite difficult to make a purchase decision as a result of so many available options. Consumer Behaviour entails the study of people 's needs, motivations, and thought processes used in choosing one product over another and the patterns of purchasing different goods and services (Orji et al., 2017). There are several factors in the background playing a significant role to take customers to the final decision. Therefore, it is very crucial for the marketing team to understand the factors that influence the customers purchasing process and buying decision (Khaniwale, 2015, Noel, 2017, Al-Salamin \& Al-Hassan, 2016). In doing so, this paper tests empirically the relationship between various factors including Price, Motivation, Perceived Cultural Importance and its impact on the consumer buying Behaviour in Saudi Arabia. As there is no sufficient empirical research done on it. This study also incorporates religious orientation as a mediator on the relationship between Price, Motivation, Perceived Cultural Importance and consumer buying Behaviour.

Even though, the succeeding movement of consumer protection has enabled the urgent needs to detain the buying decisions of consumers and how consumers make their consumption decisions. Consumers' preferences have been transforming over a prior of time with evolving trends and fashions. However, research to study the consumers buying Behaviour will reveal consumers' preferences, and it will help marketing managers to evolve their marketing strategies align with consumers' preferences. Therefore, this study is important for marketing officials and those firms which are doing business in KSA and particularly in Jeddah for effective market segmentation.

\section{Price}

Price refers to an element of exchange, or a deal that takes place among two parties normally indicate as a buyer and a seller, it denotes as what must be given up by the buyer to the seller to attain something presented (Ejye 1997). The impact of price and purchase Behaviour depends on the choice of the decisions, but, other factors can also influence, such as testimonials, price insensitivity, and willingness of a brand to be the favourite (Story \& Hess, 2006). The techniques of sales promotions affect consumers before deciding; consumers consider whether a promotion exists that helps to decide which product to purchase when two products are equally attractive (Alvarez \& Casielles, 2005). DelVecchio et al. (2007) invented that price frames affect perceptions of consumers' promoted price and the value they carry at the promoted price. Previous studies have proved the effect of price on consumer buying Behaviour (Al-Salamin \& Al-Hassan, 2016, Aschemann-Witzel, Jensen, Jensen, \& Kulikovskaja, 2017, Huck \& Wallace, 2015, Waheed, et.al. 2017). Based on the earlier discussion, the following hypotheses have been proposed:

H1a: There is a relationship between price and consumer buying Behaviour

H1b: There is a relationship between price and religious orientation

H1c: Religious orientation mediates the relationship between price and consumer buying Behaviour.

\section{Motivation}

Maslow articulated the hierarchy of needs according to the five ranks of important needs. The elementary needs come at the bottom of the hierarchy which is physiological needs while at the top of the hierarchy are the needs of self-actualisation. Nonetheless, these needs do not need to be completely fulfilled. It is a global dilemma that the more we get, the lesser the proportion of satisfaction will be which is essential for upper needs to arise (Anderson et al., 1998).

Above and beyond motivation, the decision-making process of the consumer is affected by numerous other factors in real life (Svatosová, 2013). Therefore, marketing experts should apprehend such effects and their relative importance permissible to be capable of making effectual marketing strategies. At this juncture, a significant role played by social conditions, demands and supplies, habits, and finally the selling techniques as well as technology. Staring from the thought process of buying till the purchase decision, the job of a marketing specialist is to recognise the process of stimulation in customers' mind. 
Moreover, the factors which influence consumer Behaviour divided into two groups, external and internal factors. External factors comprise of cultural, social and demographic factors while the internal factors contain subjective and psychosomatic factors. However, purchasing decision of each individual is inspired by four psychosomatic factors, which are; learning, motivation, perception, and attitude. From this, motivation is one of these factors that play a significant role when customers decide for ultimate purchase. However, it epitomises one of the factors which influence consumer buying Behaviour (Orji et al., 2017). Based on the earlier discussion, the following hypotheses have been proposed:

H2a: There is a relationship between motivation and consumer buying Behaviour.

$\mathrm{H} 2 \mathrm{~b}$ : There is a relationship between motivation and religious orientation.

H2c: Religious orientation mediates the relationship between motivation and consumer buying Behaviour.

\section{Perceived Cultural Importance}

Keesing (1981) defined culture as a collective system of aptitude between a group of people involving individual's beliefs, norms, values, and Behaviours. The ultimate outcome of culture is a set of beliefs which frequently detained by members of the culture. For instance, Prentice and Miller (1993) in their study found that merely a small proportion of college freshmen discover drinking alcohol is pleasant, while the most of them believed that majority of other freshmen adore drinking alcohol. In another research on personality by Terracciano et al. (2005), individuals from 49 cultures regarded a typical member of their identical culture on the basis of big five personality traits' dimensions. The assessments were accumulated across individuals in every culture and matched with the combined selfreport personality assessments of members in the same culture (Bezzaouia \& Joanta, 2016). However, there was an inadequate relationship between perceived and concrete personality, when those two sets of aggregate assessments were matched across cultural groups. Based on the earlier discussion, the following hypotheses have been proposed:

H3a: There is a relationship between perceived cultural importance and consumer buying Behaviour.

$\mathrm{H} 3 \mathrm{~b}$ : There is a relationship between perceived cultural importance and religious orientation.

H3c: Religious orientation mediates the relationship between perceived cultural importance and consumer buying Behaviour.

\section{Religious Orientation}

Religion is an important cultural factor to study because it is one of the most universal and influential social institutions that have significant influence on people's attitudes, values and Behaviours at both the individual and societal levels (Mokhlis, 2009, Daniele, Adam, Naomi, \& David, 2016). Based on the above, Saudi Arabia is one of the Middle Eastern countries which follow the religion of Islam (MoHE, 2010). Therefore, Islam plays an important role in national culture; it is an influential element in social and political aspects of the society (Tayeb, 1997). In Saudi Arabia, Islam plays a substantial role in buying Behaviours of consumers. This is because marketers need to duly recognise the components that can potentially satisfy Saudi consumers. Previous researchers discussed the importance of the role of religious orientation in making an effect in consumer buying Behaviour models (Yousaf \& Shaukat Malik, 2013, Dursun, 2014, Vahdati, Mousavi, \& Tajik, 2015). Based on the earlier discussion, the following hypotheses have been proposed:

H4: There is a relationship between religious orientation and consumer buying Behaviour.

\section{Methodology \\ Sample}

For this study, the questionnaire is the main tool which has been used in this study to understand the Saudi Consumers' attitudes and adoption Behaviour towards purchase cars. From this, to provide accuracy data from car agencies in Riyadh this study has been used self-administered questionnaire each section applied five-point Likert scale, ranging from (1) "strongly disagree" to (5) "strongly agree". A total of 395 usable questionnaires were returned. Non-probability sampling technique was used where no inference concerning the population needs to be made (convenience sampling) which is applicable when the study covers a large size of the sample, the population is not homogeneous, and the sampling frame is not available (Awang, 2012). The study used Partial-least-square PLS (PLS-SEM) technique, the process of 
PLS analysis follows two steps which contain the assessments of the measurement model and the structural model.

\section{Measures}

The questionnaire consisted of six sections. The first section is about respondent's profile such as age; the second section included consumer buying Behaviour, the third section also included price, the fourth section contained motivation, the fifth section involved perceived cultural importance, while the sixth section contained religious orientation. The dependent construct in the analysis was consumer buying Behaviour as measured by six items adapted from Bloch et al. (1986), and measured on a fivepoint Likert scale, where the extremes are (1) strongly disagree to (5) strongly agree. The price was included as an independent variable and measured using five items adapted from Voss et al. (1998), the respondents were asked to rate their responses on a 5-point Likert scale from (1) strongly disagree to (5) strongly agree. Motivation also included as an independent variable and measured using six items, were adapted from Cruz et al. (2009) and measured on a 5-point Likert scale from (1) strongly disagree to (5) strongly agree. Another independent variable included perceived cultural importance, in total, eight items were adapted from Wan et al. (2007) and measured on a 5-point Likert scale from (1) strongly disagree to (5) strongly agree. Finally, religious orientation was included as a mediator variable and measured by seven items adapted from Allport and Ross (1967) using a 5-point Likert scale from (1) strongly disagree to (5) strongly agree.

\section{Results}

Following the two-steps, Partial Least Squares (PLS-SEM) technique proposed by (Hair et al., 2014), both measurement model and structural model were examined for data analysis. The first step was convergent, and discriminant validity has been assessed by measuring the values of composite reliability and average variance extracted (AVE). Additionally, the indicator reliability is measured by crossloadings and outer loadings. The measurement model is assessed based on threshold proposed by (Hair et al., 2014; Hair et al., 2016; Hair et al., 2012). Table 1, and Table 2 show the measurement model with its structural variables.

To confirm the measurement model, Table 1 displays that the values of composite reliability for each variable are in between 0.832 to 0.955 . These values exceeded the minimum threshold value 0.70 which is recommended by (Hair et al., 2014). On the other hand, AVE values for each latent construct are in between 0.554 and 0.783 , which indicates a decent level of the construct validity of the measurement which is used for this study. These findings approve the convergent validity of the outer model. Discriminant validity of the measurement was also endorsed by using the technique of Fornell and Larcker (1981). Table 2 demonstrated that the square root of AVE for all the latent constructs are positioned at the diagonal matrix of the correlation matrix. Since the diagonal values are greater than the supplementary elements of the rows and columns in which they are positioned, this ratifies the discriminant validity of the outer model.

In the next step, a structural model was analysed to test the hypotheses. By running the PLS algorithm, the hypothesised model has been tested. Furthermore, path coefficients are generated. To conclude either the path coefficients are statistically significant or not, the current study applied bootstrapping technique entrenched with the Smart-PLS. Moreover, with the intention of obtaining the statistical t-value and the standard error, the bootstrapping was run with 5000 samples, and 395 cases and subsequently p-values are also created as detailed in table 3.

Table 1: The Convergent Validity Analysis

\begin{tabular}{cccccc}
\hline Constructs & Items & Loadings & CR & AVE & Cronbach's alpha \\
\hline CBB & CBB42 & 0.748 & 0.850 & 0.587 & 0.765 \\
& CBB43 & 0.842 & & & \\
& CBB44 & 0.737 & & & \\
& CBB46 & 0.732 & & 0.734 \\
MOT & MOT32 & 0.713 & 0.832 & 0.554 & \\
& MOT33 & 0.789 & & &
\end{tabular}

www.jbrmr.com A Journal of the Academy of Business and Retail Management (ABRM) 


\begin{tabular}{|c|c|c|c|c|c|}
\hline & MOT34 & 0.744 & & & \\
\hline & МOT35 & 0.727 & & & \\
\hline \multirow[t]{6}{*}{ PCI } & PCI49 & 0.885 & 0.955 & 0.780 & 0.943 \\
\hline & PCI50 & 0.928 & & & \\
\hline & PCI51 & 0.841 & & & \\
\hline & PCI52 & 0.939 & & & \\
\hline & PCI53 & 0.807 & & & \\
\hline & PCI55 & 0.888 & & & \\
\hline \multirow[t]{5}{*}{ PRC } & PRC37 & 0.869 & 0.947 & 0.783 & 0.931 \\
\hline & PRC38 & 0.909 & & & \\
\hline & PRC39 & 0.889 & & & \\
\hline & PRC40 & 0.910 & & & \\
\hline & PRC41 & 0.845 & & & \\
\hline \multirow[t]{4}{*}{$\mathrm{RO}$} & RO26 & 0.770 & 0.914 & 0.727 & 0.875 \\
\hline & $\mathrm{RO} 28$ & 0.870 & & & \\
\hline & $\mathrm{RO} 29$ & 0.899 & & & \\
\hline & RO30 & 0.864 & & & \\
\hline
\end{tabular}

Note: CBB: Consumer Buying Behaviour, MOT: Motivation, PCI: Perceived Culture Importance, PRC: Price, RO: Religious Orientation.

Table 2: Discriminant Validity Analysis

\begin{tabular}{cccccc}
\hline Constructs & CBB & MOT & PCI & PRC & RO \\
\hline CBB & $\mathbf{0 . 7 6 6}$ & & & & \\
MOT & 0.417 & $\mathbf{0 . 7 4 4}$ & & & \\
PCI & -0.208 & -0.163 & $\mathbf{0 . 8 8 3}$ & & \\
PRC & 0.420 & 0.518 & -0.214 & $\mathbf{0 . 8 8 5}$ & \\
RO & -0.087 & -0.030 & 0.225 & -0.110 & $\mathbf{0 . 8 5 2}$ \\
\hline
\end{tabular}

Note: CBB: Consumer Buying Behaviour, MOT: Motivation, PCI: Perceived Culture Importance, PRC: Price, RO: Religious Orientation.

As shown in Table 3, motivation has a positive and significant impact on consumer buying Behaviour $(\beta=0.266, t=4.878)$. Although, the relationship between motivation and consumer buying Behaviour is not supported $(\beta=0.052, t=0.885)$. Whereas, the mediating impact of religious orientation in between motivation and consumer buying Behaviour is not a significant and negative relationship ( $\beta=$ $0.001, t=-0.220$ ). Perceived culture importance has a positive and significant impact on consumer buying Behaviour $(\beta=-0.104, t=2.530)$. In addition to that, perceived culture importance has a positive and significant impact on religious orientation $(\beta=0.215, \mathrm{t}=2.836)$. While, religious orientation does not mediate the relationship between perceived cultural importance and consumer buying Behaviour $(\beta=-$ $0.006, \mathrm{t}=-0.563)$. Moreover, there is a positive and significant impact of price on consumer buying Behaviour $(\beta=0.258, t=5.156)$. Price has a positive impact on religious orientation $(\beta=-0.091, t=1.380)$. Whereas, religious orientation as a mediator is not significant in the relationship between price and consumer buying Behaviour $(\beta=0.003, t=0.579)$. Finally, the relationship between religious orientation and consumer buying Behaviour is not significant $(\beta=-0.028, \mathrm{t}=0.599)$. 
Table 3: Results of the Inner Structural Model

\begin{tabular}{|c|c|c|c|c|c|}
\hline Hypothesis & Beta & Std-Error & T-Value & $\begin{array}{c}\text { P- } \\
\text { Value }\end{array}$ & Decision \\
\hline MOT -> CBB & 0.266 & 0.054 & 4.878 & & Supported \\
\hline MOT -> RO & 0.052 & 0.059 & 0.885 & & Not supported \\
\hline PCI -> CBB & -0.104 & 0.041 & 2.530 & & Supported \\
\hline PCI -> RO & 0.215 & 0.076 & 2.836 & & Supported \\
\hline PRC $->$ CBB & 0.258 & 0.050 & 5.156 & & Supported \\
\hline PRC -> RO & -0.091 & 0.066 & 1.380 & & Supported \\
\hline $\mathrm{RO}->\mathrm{CBB}$ & -0.028 & 0.046 & 0.599 & & Not supported \\
\hline MOT -> RO -> CBB & -0.001 & 0.004 & -0.220 & & Not supported \\
\hline $\mathrm{PCI}->\mathrm{RO}->\mathrm{CBB}$ & -0.006 & 0.011 & -0.563 & & Not supported \\
\hline PRC $>$ RO $>$ CBB & 0.003 & 0.006 & 0.579 & & Not supported \\
\hline
\end{tabular}

\section{Discussion}

This paper shed light on the interrelation between four important factors in consumer buying Behaviour: price, motivation, perceived culture importance, and religious orientation. The empirical findings of this study confirm the direct relationship between motivation (MOT->CBB), price (PRC$>\mathrm{CBB}$ ), perceived culture importance and consumer buying Behaviour (PCI->CBB). Moreover, the direct relationship between perceived culture importance (PCI->RO), price and religious orientation (PRC->RO). Based on this, the price is one of the most important determinants of consumer buying Behaviour in Riyadh. Moreover, the finding regarding the effect of price dimensions in this case "work" on consumer buying behaviour is in line with the Theory of Planned Behaviour, which shows that to some extent perceived Behavioural control can determine consumer buying Behaviour. This result is also in line with previous studies (Oeconomiae, 2008, Al-Salamin \& Al-Hassan, 2016; Aschemann-Witzel et al., 2017; Huck \& Wallace, 2015) who investigate the relationship between price and consumer buying Behaviour. These studies established a significant positive relationship between various facets of price and consumer buying Behaviour. Indicating that prices decreased consumers' recalled total cost and increased their purchase intentions. However, the effects of price information and price cognitions on positive and neutral emotions are basically influenced positive and neutral emotions of consumer behaviour. From this, the findings have proved the influence of price on religious orientation as this study conducted in the Kingdom of Saudi Arabia where Islam encourages people to have a reasonable price for any product.

The results also indicated that motivation is one of the most important determinants of consumer buying Behaviour in Saudi Arabia. This result corresponds with past research work (Chen et al., 2010) who found that motivation may automatically develop owing to the close proximity at work, interactions and shared experiences which can lead to the improvement of consumer buying Behaviour. As mentioned by Kellett (2013) there are several opportunities for improving the consumer buying Behaviour in Riyadh, but they must improve the way of motivation to motivate consumer buying Behaviour. In contrast, the empirical evidence found that motivation is not related to the religious orientation in Riyadh which is not at par as compared to the standards in the industry to improve the consumer buying Behaviour. The result is inconsistent with the previous studies by Chen et al. (2010), and Kellett (2013) who found that motivation has a full impact on religious orientation regarding support and motivate consumers in their daily life. The current result shows that religious orientation does not motivate car consumers in Riyadh. As they are found to be more novelty seeking where brand and quality conscious element of their Behaviour was demonstrated by the importance attributed to well-known national brands, high quality and latest style products, and a high standard of product expectations (Kamaruddin, 2007, Orji et al., 2017).

The findings also suggest that perceived culture importance is one of the most important determinants of consumer buying Behaviour. This is consistent with the other studies that cultural factors significantly influence consumers' impulsive buying Behaviour (Bezzaouia \& Joanta, 2016). Specifically, 
the theory of individualism and collectivism holds important insights about consumer Behaviour that can help us to gain a better and more complete understanding of the impulsive buying phenomenon (Jam et al., 2013). In Saudi Arabia, the similarity of cultural background and social class affirmed consumer buying Behaviour as they have common interests and Behaviour. Similarly, the relationship between perceived culture importance and religious orientation found to be supported, and consistent with the previous study by (Mokhlis, 2009) who suggest that religion is an important cultural factor to study, because it is one of the most universal and influential social institutions that have significant influence on people's attitudes, values and Behaviours at both the individual and societal levels.

The indirect relationships also were tested empirically where found that the mediating role of religious orientation in the relationship between price, motivation, perceived culture importance and consumer buying Behaviour is not supported. This means that consumers buying Behaviour in Saudi Arabia are influenced more by the nature of the product, the degree of perceived risk in the product class, the amount of information search, store location, product assortment and store image rather than religious orientation. Even though, Islam in Saudi Arabia plays an important role in the peoples' day-to-day lives but globalisation and changes in the international environment has some impacts on Saudi people, where people respond to the modernization to gain status or social prestige from the acquisition and consumption of goods and to provide prominently visible evidence of their ability to purchase expensive products (Al-Hyari, 2012).

From this, the purchasing decision can be categorized according to how much consumers adhere to a faith. However, marketing strategists could develop programs that would enhance the important values of consumers in each market segment (Essoo \& Dibb, 2004). On the other hand, it is evident that the relationship between religious orientation and consumer buying Behaviour is not supported. This is inconsistent with the previous studies as such (Al-Hyari, 2012; Muhamad \& Mizerski, 2010; Kamaruddin, 2007; Vitell et al., 2007; Delener, 1994; Essoo \& Dibb, 2004, Yousaf \& Shaukat Malik, 2013, Dursun, 2014). This means that the purchase decision is the reflection of an individual's feelings and thoughts. This is related to the lack of understanding of religious orientation and consumer buying Behaviour. Which is supported by, Alajmi et al. (2011) that there is a need to develop a better understanding of religious orientation. To do so, it is vital to examine the personal factors and social factors that influence the buyer's Behaviour to implement effective marketing strategies and launch smarter marketing plans (Khaniwale, 2015).

\section{Conclusion and Implications}

As to date, this study is one of the very few studies conducted in Riyadh to examine the effects of price, motivation, perceived culture importance and religious orientation on consumer buying Behaviour. In this manner, the present study adds an extension to the literature on consumer buying Behaviour in Saudi Arabia as well as other Muslim countries, as the previous studies have been mostly conducted in the West. The findings of the study are important for the development of public transportation in Saudi Arabia in general, and in Riyadh in specific, where little research has been done before. The findings from the study can help in the development of human capital policies, management practices and management development programs that can elicit consumer buying Behaviour. Thus, this study can potentially assist in the transformation process towards effective public transportation. Automobile markets in Saudi Arabia prove itself to be one of the most successful and dynamic markets. For that reason, this study provides evidence for the application of the conceptual model and contributes to the existing body of knowledge on religious orientation and its influence on consumer buying Behaviour. Understanding customers' wants and needs are helpful to the marketers and the governments to develop suitable strategies to improve the local markets (Kanagal, 2009).

\section{Limitations and directions for future studies}

This study acknowledges some limitations to be considered. This study focused only on Saudi Arabia as an Islamic country, so results derived from this study may not be generalized for other Islamic countries. Moreover, this study focused only on one sector, which are car agencies. In addition, this research investigated the role of few variables such as price, motivations, perceived cultural importance and religious orientation in effecting the buying Behaviour of the consumer. Therefore, based on the 
aforementioned limitations, this study has also had recommendations for future studies. Future researches are encouraged to incorporate the effect of many other variables to further explain consumer buying Behaviour. In addition, future studies in Kingdom of Saudi Arabia or other Islamic countries may examine the same model of this study with few changes in other sectors, such as service and industry sectors. And for further investigations, this model can be tested empirically using data collected from other Islamic countries.

\section{References}

Ajzen, I. (1988). Attitudes, personality and behavior. Open University Press, Milton Keynes.

Alajmi, S., Dennis, C., \& Altayab, Y. (2011). The effect of national culture on service provision within Takaful industry: A comparative study in Kuwait and Egypt. Journal of Islamic Marketing, 2(3), 225-245.

Al-Hyari, K., Alnsour, M., Al-Weshah, G., \& Haffar, M. (2012). Religious beliefs and consumer behaviour: from loyalty to boycotts. Journal of Islamic Marketing, 3(2), 155-174.

Allport, G. W., \& Ross, J. M. (1967). Personal religious orientation and prejudice. Journal of personality and social psychology, 5(4), 432-443.

Al-Salamin, H., \& Al-Hassan, E. (2016). The Impact of Pricing on Consumer Buying Behavior in Saudi Arabia : AlHassa Case Study European Journal of Business and Management 8(12), 62-73.

Alvarez Alvarez, B., \& Vázquez Casielles, R. (2005). Consumer evaluations of sales promotion: the effect on brand choice. European Journal of Marketing, 39(1/2), 54-70.

Anderson, P. M., \& He, X. (1998). Price influence and age segments of Beijing consumers. Journal of Consumer Marketing, 15(2), 152-169.

Aschemann-Witzel, J., Jensen, J. H., Jensen, M. H., \& Kulikovskaja, V. (2017). Consumer behaviour towards pricereduced suboptimal foods in the supermarket and the relation to food waste in households. Appetite, 116, 246258.

Awang, Z. (2012). Research methodology and data analysis. Penerbit Universiti Teknologi: MARA Press.

Bezzaouia, M., \& Joanta, A. R. (2016). The Relationships between Cultural Values and Consumer Motivations For Purchasing Luxury Brands. Ecoforum Journal, 5(1).

Bloch, P. H., Sherrell, D. L., \& Ridgway, N. M. (1986). Consumer search: An extended framework. Journal of consumer research, 13(1), 119-126.

Cavana, R. Y., Delahaye, B. L., \& Sekaran, U. (2001). Applied business research: Qualitative and quantitative methods. Australia: John Wiley \& Sons.

Chen, G., Kirkman, B. L., Kim, K., Farh, C. I., \& Tangirala, S. (2010). When does cross-cultural motivation enhance expatriate effectiveness? A multilevel investigation of the moderating roles of subsidiary support and cultural distance. Academy of Management Journal, 53(5), 1110-1130.

Chowdhury, A., \& Shil, N. C. (2017). Public Sector Reforms and New Public Management: Exploratory Evidence from Australian Public Sector. Asian Development Policy Review, 5(1), 1-16.

Cruz, N. M., Martín Pérez, V., \& Trevilla Cantero, C. (2009). The influence of employee motivation on knowledge transfer. Journal of knowledge management, 13(6), 478-490.

Daniele, M., Adam, B. C., Naomi, M., \& David, G. M. (2016). The Effects of Religion on Consumer : A Conceptual Framework and Research Agenda. Journal of Consumer Psychology.

Delener, N. (1994). Religious contrasts in consumer decision behaviour patterns: their dimensions and marketing implications. European Journal of Marketing, 28(5), 36-53.

DelVecchio, D., Krishnan, H. S., \& Smith, D. C. (2007). Cents or percent? The effects of promotion framing on price expectations and choice. Journal of marketing, 71(3), 158-170.

Dursun, Y. (2014). The Effect of Religiosity on Product Involvement in a Muslim Society Journal of Business ResearchTürk, 6(1), 58-69

Echtner, C. M., \& Prasad, P. (2003). The context of third world tourism marketing. Annals of Tourism Research, 30(3), 660-682.

Ejye O. (1997). Target pricing: a marketing management tool for pricing new cars. Pricing Strategy and Practice, 5(2), 61-69.

Essoo, N., \& Dibb, S. (2004). Religious influences on shopping behaviour: An exploratory study. Journal of Marketing Management, 20(7-8), 683-712.

Factors on Consumer Buying Behaviour towards Textile Materials in South Eastern Nigeria. International Journal of Business and Economics Research, 6(1), 7.

Fishbein, M. Ajzen, I. (1975). Belief, Attitude, Intention, and Behaviour: An Introduction to Theory and Research. Massachusetts: Addison-Wesley.

Fornell, C., \& Larcker, D. F. (1981). Evaluating structural equation models with unobservable variables and measurement error. Journal of marketing research, 39-50. 
Hair F Jr, J., Sarstedt, M., Hopkins, L., \& G. Kuppelwieser, V. (2014). Partial least squares structural equation modeling (PLS-SEM) An emerging tool in business research. European Business Review, 26(2), 106-121.

Hair Jr, J. F., Hult, G. T. M., Ringle, C., \& Sarstedt, M. (2016). A primer on partial least squares structural equation modeling (PLS-SEM). Sage Publications.

Hair, J. F., Sarstedt, M., Pieper, T. M., \& Ringle, C. M. (2012). The use of partial least squares structural equation modeling in strategic management research: a review of past practices and recommendations for future applications. Long range planning, 45(5), 320-340.

Huck, S., \& Wallace, B. (2015). The impact of price frames on consumer decision making: Experimental evidence. Experimental evidence, 1-47.

Jam, F. A., Saeed, I., Ullah, A., Arif, M., \& Gul, H. (2013). National Culture as a Moderator between International Diversification Strategy and Performance. IJCBS.

Kamaruddin, A. R. (2007). Religiosity and shopping orientation: a comparative study of Malaysian and Thailand consumers. Journal of Global Business Management, 3(2), 1-13.

Kanagal, N. (2009). Role of relationship marketing in competitive marketing strategy. Journal of Management and Marketing Research, 2(1), 1-17.

Kaplan, A. M., \& Haenlein, M. (2009). The increasing importance of public marketing: Explanations, applications and limits of marketing within public administration. European Management Journal, 27(3), 197-212.

Keesing, R. M. (1981). Cultural anthropology: A contemporary perspective. Holt McDougal.

Kellett, A. (2013). Combat motivation: The behaviour of soldiers in battle. Springer Science \& Business Media.

Khanfir, W. (2017). Can Contractionary Fiscal Policy be Expansionary? Evidence from Tunisia. Asian Journal of Economic Modelling, 5(2), 223-232.

Khaniwale, M. (2015). Consumer buying behavior. International Journal of Innovation and Scientific Research, 14(2), 278-286.

Kotle, P. (2001). Marketing Management Millenium Edition (Tenth Edition ed.): Pearson Custom Publishing.

Krejcie, R. V., \& Morgan, D. W. (1970). Determining sample size for research activities. Educational and psychological measurement, 30(3), 607-610.

Lai, C. F. (2016). Tariff, Consumption Home Bias and Macroeconomic Dynamics. Asian Economic and Financial Review, 6(8), 425-444.

MoHE. (2010). Ministry of higher education Saudi Arabia country background 2010. Riyadh King Saud University.

Mokhlis, S. (2009). Relevancy and measurement of religiosity in consumer behavior research. International Business Research, 2(3), p75-84.

Muhamad, N., \& Mizerski, D. (2010). The constructs mediating religions' influence on buyers and consumers. Journal of Islamic Marketing, 1(2), 124-135.

Noel, H. (2017). Basics marketing 01: Consumer behaviour: Bloomsbury Publishing.

Oeconomiae, D. (2008). The role of price affect in behavioral pricing research: Essays on the antecedents and consequences of consumers' emotional responses to price information (Doctoral dissertation, University of St. Gallen).

Orji, M. G., Sabo, B., Abubakar, M. Y., \& Usman, A. D. (2017). Impact of Personality

Prentice, D. A., \& Miller, D. T. (1993). Pluralistic ignorance and alcohol use on campus: some consequences of misperceiving the social norm. Journal of personality and social psychology, 64(2), 243.

Sangroya, D., \& Nayak, J. K. (2017). Factors influencing buying behaviour of green energy consumer. Journal of Cleaner Production, 151, 393-405.

Sekaran, U., \& Bougie, R. J. (2016). Research methods for business: A skill building approach. John Wiley \& Sons.

Shih, Y.-Y., \& Fang, K. (2006). Effects of network quality attributes on customer adoption intentions of internet banking. Total Quality Management \& Business Excellence, 17(1), 61-77.

Singh, K. S. D., \& Islam, M. A. (2017). Gauging Malaysian Consumers Perspectives about Corporate Social Responsibility. Asian Economic and Financial Review, 7(7), 737-747.

Story, J., \& Hess, J. (2006). Segmenting customer-brand relations: beyond the personal relationship metaphor. Journal of Consumer Marketing, 23(7), 406-413.

Svatosová, V. (2013). Motivation of online buyer behavior. Journal of Competitiveness, 5(3), 14-30.

Tayeb, M. (1997). Islamic revival in Asia and human resource management. Employee Relations, 19(4), $352-364$.

Terracciano, A., Abdel-Khalek, A. M., Adam, N., Adamovova, L., Ahn, C.-k., Ahn, H.-n., Angleitner, A. (2005). National character does not reflect mean personality trait levels in 49 cultures. Science, 310(5745), 96-100.

Vahdati, H., Mousavi, N., \& Tajik, Z. M. (2015). The Study of Consumer Perception on Corporate Social Responsibility towards Consumers Attitude and Purchase Behavior, Asian Economic and Financial Review, 5(5), 831-845.

Verhoef, P. C. (2003). Understanding the effect of customer relationship management efforts on customer retention and customer share development. Journal of marketing, 67(4), 30-45.

Vitell, S. J., Singh, J. J., \& Paolillo, J. G. (2007). Consumers' ethical beliefs: The roles of money, religiosity and attitude 
toward business. Journal of Business Ethics, 73(4), 369-379.

Voss, G. B., Parasuraman, A., \& Grewal, D. (1998). The roles of price, performance, and expectations in determining satisfaction in service exchanges. The Journal of Marketing, 46-61.

Waheed, A., Yang, J., Ahmed, Z., Rafique, K., \& Ashfaq, M. (2017). Is Marketing Limited to Promotional Activities? The Concept of Marketing: A Concise Review of the Literature. Asian Development Policy Review, 5(1), 56-69.

Wan, C., Chiu, C.-y., Tam, K.-p., Lee, S.-1., Lau, I. Y.-m., \& Peng, S. (2007). Perceived cultural importance and actual self-importance of values in cultural identification. Journal of personality and social psychology, 92(2), 337.

Warburton, J., \& Terry, D. J. (2000). Volunteer decision making by older people: A test of a revised theory of planned behavior. Basic and Applied Social Psychology, 22(3), 245-257.

Yousaf, S., \& Shaukat Malik, M. (2013). Evaluating the influences of religiosity and product involvement level on the consumers. Journal of Islamic Marketing, 4(2), 163-186. 